\title{
Corrosion of Steel in Concrete and Its Prevention in Aggressive Chloride-Bearing Environments
}

\author{
Luca Bertolini, Maddalena Carsana, Matteo Gastaldi, Federica Lollini, and Elena Redaelli \\ Department of Chemistry, Materials and Chemical Engineering "Giulio Natta", Politecnico di Milano, Italy
}

\begin{abstract}
This keynote paper deals with the durability of reinforced concrete $(R C)$ structures exposed to aggressive environments characterized by high concentration of chloride ions, namely, marine environments or the use of de-icing salts. The mechanism of chloride-induced corrosion of steel in concrete is introduced, and its influence on the service life of RC structures is analyzed. Factors affecting the time to corrosion initiation are described with regard to both concrete properties and environmental exposure conditions. Design approaches available for achieving durability targets associated with the design service life are analyzed, focusing on studies carried out by the authors in recent years at the $\mathrm{MCD}$ Concrete Durability lab of Politecnico di Milano, which were aimed at improving the protection provided to the steel bars by the concrete cover, investigating the advantages of using corrosion-resistant stainless steel bars and developing the electrochemical technique of cathodic prevention.
\end{abstract}

\section{INTRODUCTION}

Worldwide, corrosion of steel reinforcing bars is the major cause of premature failure of reinforced concrete (RC) structures, especially in chloride environments (Bertolini, Elsener, Pedeferri, Redaelli, \& Polder, 2013; Page \& Page, 2007). Durability is a critical issue in the management of these structures, and great efforts are made by structural designers and materials engineers to prevent corrosion of steel reinforcing bars (rebars). Specific design tools and preventative techniques have been developed for the prevention of steel corrosion since the design stage. Furthermore, durability issues are often interrelated to sustainability targets, not only because the increase of durability in itself improves the sustainability of structures (by reducing the need for repair or replacement works in time) but also because several durability strategies may allow recycling of wastes and the reduction of the use of natural resources. This paper, after analyzing the mechanisms of corrosion of steel in reinforced concrete structures, describes possible approaches for the design of durable structures. Being unfeasible to consider all the aspects related to this comprehensive topic in a single manuscript, the attention is focused on the contributions that the $m C D$ Concrete Durability group of Politecnico di Milano has given in recent years on three main strategies against chloride-induced corrosion: (a) the improvement of permeability of the concrete cover, (b) the use of stainless steel bars, and (c) the application of the technique of cathodic prevention. The authors wish to dedicate this paper to Prof. Pietro Pedeferri, who passed away on 3 December 2008; besides giving an outstanding contribution to the study of corrosion of steel in concrete (Bertolini, 2011), he paved the way for the research works mentioned in this paper.

\section{CORROSION BEHAVIOUR OF STEEL IN CONCRETE}

\subsection{Passivity}

Steel in concrete is normally protected by the alkaline solution contained in the pores of the hydrated cement paste (with $\mathrm{pH}$ values higher than 13), which promotes passivation, i.e., the formation of a spontaneous thin protective oxide film on the surface of the steel (Arup, 1983; Page \& Treadaway, 1982). Figure 1a, for instance, shows the evolution in time of the corrosion rate of steel bars embedded in concrete; it can be observed that in a few days, the steel reaches corrosion rate values lower than $1 \mathrm{~mA} / \mathrm{m}^{2}$ (corresponding to a depletion of about $1 \mu \mathrm{m} /$ year), which characterize the passive behaviour of steel. Figure $1 \mathrm{~b}$ shows the typical anodic and cathodic polarization curves for passive steel in concrete under different exposure conditions. Although the alkalinity of concrete may be slightly influenced by the type of cement (e.g., blended cement are characterized by lower alkalinity than Portland cement), it is sufficient to promote negligible corrosion rate $\left(i_{\text {corr }}\right)$, regardless of the presence of oxygen and moisture in the concrete pores.

Only in very specific conditions of extremely high alkalinity, which were only found in few cases associated with segregated injection grout of posttensioned structures, passivation may be lost (Carsana \& Bertolini, 2015, 2016). 


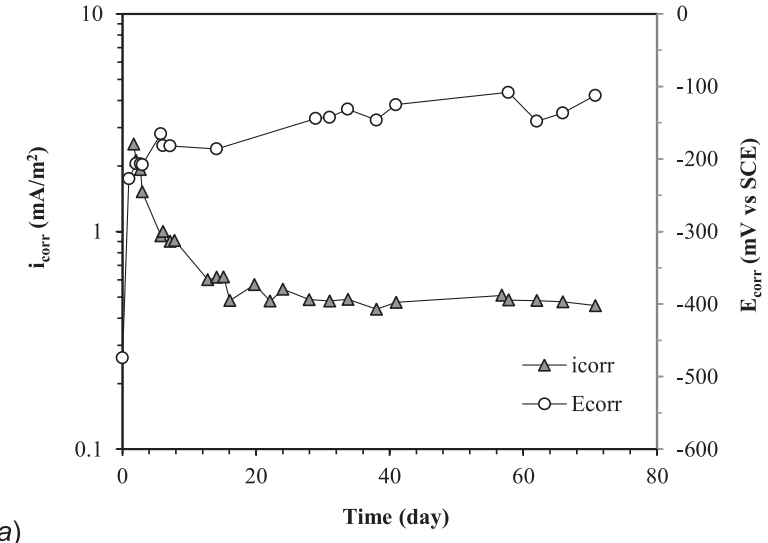

(a)

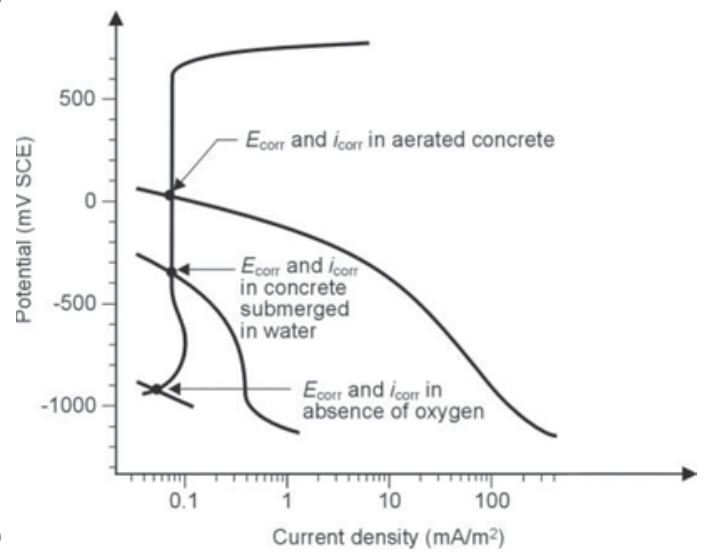

Figure 1. (a) Typical evolution in time of corrosion potential $\left(E_{\text {corr }}\right)$ and corrosion rate $\left(i_{\text {corr }}\right)$ of steel in concrete after casting. Few days after casting, passivity conditions are reached, which are characterised by corrosion rate values lower than $1 \mathrm{~mA} / \mathrm{m}^{2}$ and (in aerated concrete) corrosion potential higher than $-200 \mathrm{mV}$ vs. SCE, as shown schematically by the polarization curve of (b) (Bertolini et al., 2013).

\subsection{Mechanisms of corrosion initiation}

Corrosion on the steel bars takes place if the passive film is removed or is locally damaged. This usually occurs due to carbonation of concrete or chloride penetration. Carbonation is the neutralization of alkalinity of concrete due to carbon dioxide in the atmosphere; it brings about a drop in the $\mathrm{pH}$ of concrete from alkaline values to neutrality, with consequent loss of stability of the passive film on the steel bars. Consequently, rebars can corrode, if oxygen and moisture are available. Corrosion rate of steel in contact with carbonated concrete is strongly dependent on environmental exposure, and it especially increases as the moisture of concrete increases (Alonso, Andrade, \& Gonzales, 1988); only when the moisture content approaches saturation, the corrosion rate decreases due to lack of oxygen.

Chloride ions may locally break the passive film even in alkaline concrete. This occurs when chloride ions, which are contained, for instance, in seawater or in common de-icing salts, penetrate the concrete cover, and reach a critical threshold level at the depth of the reinforcement. Pitting corrosion thus initiates and may propagate if moisture and oxygen are available at the steel surface. Corrosion of steel bars in chloridecontaminated concrete is usually more severe than carbonation-induced corrosion, leading to much higher corrosion rates for given conditions of moisture content and temperature.

Figure 2 shows typical effects of corrosion, which may affect serviceability and safety of RC structures. Cracking, spalling, or delamination of the concrete cover may take place due to tensile stresses induced by corrosion products growing at the steel surface. In the case of chloride-induced pitting corrosion, the cross-section of the reinforcement can be significantly reduced, and thus, the load-bearing capacity of a structural element, its ductility, and seismic behaviour, as well as its fatigue strength, may be affected, even before any cracking takes place in the concrete cover.

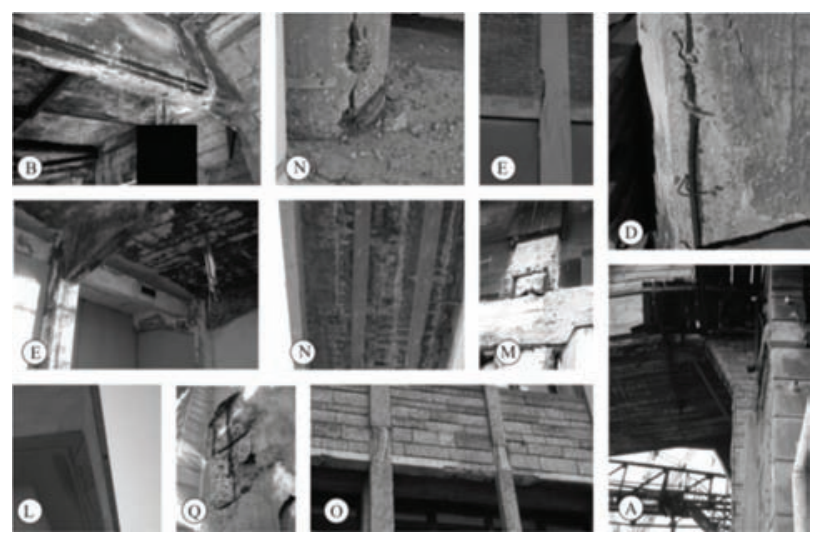

Figure 2. Typical effects of corrosion of steel bars (Bertolini, Carsana, Gastaldi, Lollini, \& Redaelli, 2011a).

Although carbonation and chloride penetration are the most frequent causes of corrosion initiation in RC structures, it is worth to remember that under specific circumstances, other forms of corrosion could take place. DC stray currents may promote corrosion initiation or propagation, e.g., in structures of railway networks (Bertolini, Carsana, \& Pedeferri, 2007), whilst high strength steels used in pre-stressed concrete may be highly vulnerable to the effects of corrosion and, under very specific environmental, mechanical, metallurgical, and electrochemical conditions, may suffer of hydrogen embrittlement (HE), which leads to brittle fracture of the steel strands or bars (Page \& Page, 2007).

\subsection{Chloride-induced corrosion}

The risk of chloride-induced corrosion is usually associated with the penetration of chlorides through the concrete cover. Pitting corrosion initiates when the penetration of chlorides in the concrete cover is such 
that a threshold value is reached at the steel surface, i.e., at the depth of the concrete cover thickness.

\subsubsection{Chloride penetration}

The rate of chloride penetration depends on many factors, the main ones being related to the concrete properties, the mechanisms of transport of chloridebearing solutions, the moisture content of concrete, and the concentration of chlorides in the environment. Transport of chlorides through the concrete cover may take place due to a combination of different transport mechanisms (diffusion, capillary suction, or permeation), and moreover, chemical binding may occur with the hydration products (CEB, 1992; Frederiksen, 1996). Thus, modelling chloride penetration in time is quite a complicated task. For example, when a structural element is exposed to wetting-drying cycles, it is subjected to capillary absorption of the chloride-bearing solution during wetting, possibly followed by diffusion during the wet period, while during dry periods, evaporation of water brings about accumulation of chlorides near the surface. Exposure to precipitations, conversely, may wash out chlorides in the surface of concrete. Chloride penetration in a reinforced concrete structure is thus a complex function of geometry, position, environment, and concrete composition.

From a practical point of view, the penetration of chlorides in concrete is often described as a diffusion phenomenon [according to Fick's second law, as first proposed by Collepardi, Marcialis, and Turriziani (1972)], and an apparent diffusion coefficient $D_{\text {app }}$ is considered, which depends on the pore structure of the concrete and on all the factors that determine it, such as w/c ratio, compaction, curing, and presence of cracks. The type of cement has also a considerable effect: passing from concrete made with Portland cement to concrete made with increasing addition of pozzolana or blast furnace slag, $D_{\text {app }}$ can be drastically reduced (Collepardi et al., 1972; Frederiksen, 1996). The apparent diffusion coefficient decreases in time, especially for slowly reacting blast furnace slag or pozzolanic cements. $D_{\text {app }}$ obtained from real structures or laboratory tests is also used as a parameter to compare the resistance to chloride penetration of different concretes, assuming that the lower the $D_{\text {app }}$ is, the higher the resistance to chloride penetration. For instance, Figure 3 compares $D_{\text {app }}$ values obtained from diffusion tests on mortars with different mineral additions, showing the beneficial effect of pozzolanic additions and the role of their fineness (measured through the specific surface: the higher the fineness of grinding, the higher is the specific surface). For instance, even waste glass, when it is finely ground, may have good pozzolanic properties and greatly improve the resistance to the penetration of chlorides (Carsana, Frassoni, \& Bertolini, 2014).

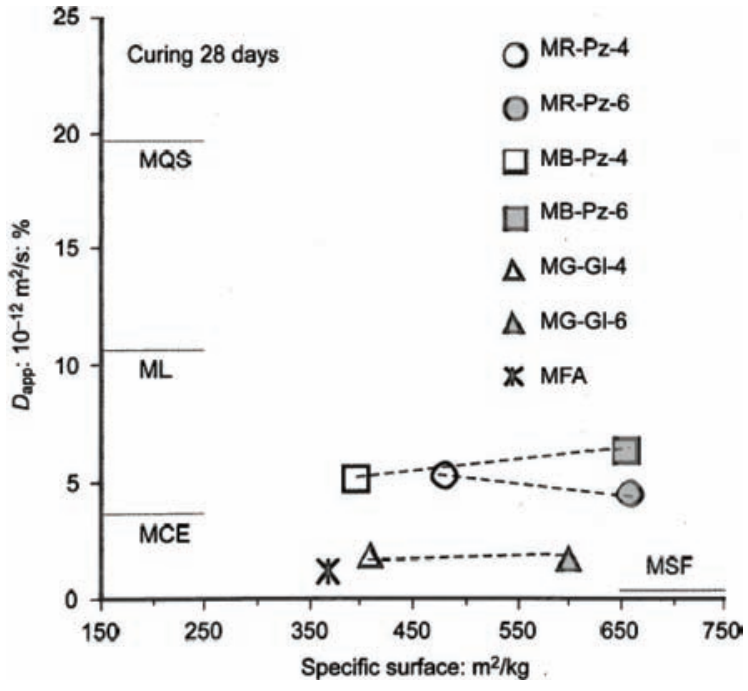

Figure 3. Apparent diffusion coefficients obtained by fitting profiles measured on specimens immersed in $150 \mathrm{~g} / \mathrm{L} \mathrm{NaCl}$ solution for 35 days (according to NT-BUILD 443 standard) on mortar specimens with Portland cement (MCE) and with different inert (MQS $=30 \%$ quartz sand and $\mathrm{ML}=30 \%$ limestone) and pozzolanic (MR-Pz $=30 \%$ red natural pozzolana, MB-Pz $=30 \%$ black natural pozzolana, MFA $=30 \%$ coal fly ash, MG-GI $=30 \%$ green glass, and $\mathrm{MSF}=10 \%$ silica fume) additions, as a function of the specific surface obtained after grinding (Bertolini et al., 2011b).

\subsubsection{Chloride threshold value}

The chloride threshold $\left(\mathrm{Cl}_{\mathrm{th}}\right)$ is usually expressed as a critical total (i.e., acid soluble) chloride content, expressed as a percentage of chlorides with respect to the mass of cement. It depends on numerous factors (Alonso \& Sanchez, 2009; Angst, Elsener, Larsen, \& Vennesland, 2009; Glass \& Buenfeld, 1997), the major ones being the electrochemical potential of the steel, the $\mathrm{pH}$ of pore solution in the concrete (which is influenced by the type of cement and mineral additions), and the presence of voids at the steel/ concrete interface.

The analysis of the role of the electrochemical potential $(E)$ of steel on $\mathrm{Cl}_{\text {th }}$ is useful for understanding several aspects of pitting corrosion initiation. In the absence of any macrocell or external currents (see ahead), $E$ mainly depends on the moisture content of concrete, which determines the availability of oxygen at the steel surface (Figure 1b). In structures exposed to the atmosphere, oxygen can easily reach the steel surface through the air filled pores, and the corrosion potential of the reinforcement is usually in the range $-100 /+100 \mathrm{mV}$ vs. $\mathrm{Cu} / \mathrm{CuSO}_{4}$.

In this case, since the early studies carried out by Vassie (1984), it was assumed that $C l_{\text {th }}$ may vary in the range of $0.4-1 \%$ by mass of cement. Many attempts were made to better define $\mathrm{Cl}_{\text {th }}$ under this exposure condition and possibly identify the role of type of binder or the microstructure of the steel-concrete interface, which however have led to conflicting results 
(Alonso \& Sanchez, 2009; Angst et al., 2009; Glass \& Buenfeld, 1997; Lollini, Redaelli, \& Bertolini, in press; Manera, Vennesland, \& Bertolini, 2008; Page, 2002), also due to different techniques used for the detection of corrosion initiation (Bertolini \& Redaelli, 2009a). When a reinforced concrete element is saturated by water, the low oxygen content in the pores brings $E$ towards more negative values (e.g., lower than $-500 \mathrm{mV}$ vs. $\mathrm{Cu} / \mathrm{CuSO}_{4}$ ), and the chloride threshold may be greater than in aerated structures, sometimes even reaching values one order of magnitude higher. For this reason, parts of RC structures permanently immersed in seawater rarely experience pitting corrosion initiation. The effect of the potential on the chloride threshold was explained by Pedeferri (1995) through the schematic graph shown in Figure 4, where the shadowed area shows conditions where pitting corrosion may initiate and the line $E_{\text {pit }}$ may be assumed as a rough indication of the trend of the chloride threshold (on the $x$-axis) as a function of the steel potential (on the $y$-axis).

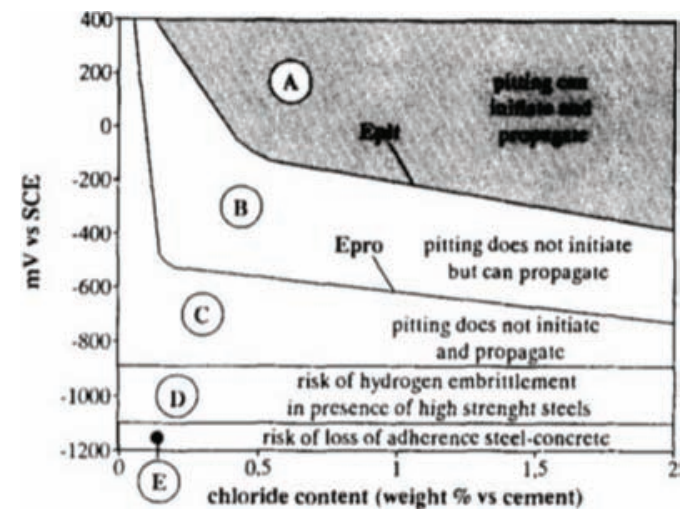

Figure 4. Pedeferri's diagram showing a schematic illustration of steel behaviour in concrete for different potentials and chloride contents (Pedeferri, 1995).

A change in the steel potential, however, may occur due to polarization effects that, consequently, can also modify $\mathrm{Cl}_{\mathrm{th}}$. Polarization effects may arise from macrocells between corroding areas and passive areas (Bertolini et al., 2013). In fact, if corroding steel is electrically connected to surrounding passive steel, the anodic process tends to concentrate on the corroding steel and the cathodic process on the passive steel. An overall increase in the corrosion rate on the active steel is thus induced by this macrocell, and it depends on the ratio between anodic and cathodic sites and the resistivity of concrete (Andrade, Maribona, Feliu, Gonzalez, \& Feliu, 1992; Schiegg, Audergon, Elsener, \& Böhni, 2001).

Macrocells can have important implications on submerged elements. In fact, if passive rebars are present on which, for any reasons, oxygen is available, a macrocell may form which will promote corrosion initiation and propagation on the bars in water-saturated concrete. For instance, in hollow marine structures with air inside, corrosion may be stimulated by a macrocell on the bars in the outer parts by inner passive bars embedded in aerated concrete, as shown in Figure 5. Similar cases can also occur in tunnels buried in chloride-contaminated soils (Redaelli, Bertolini, Peelen, \& Polder, 2006). Steel polarization may also be intentionally induced by an external current to increase $\mathrm{Cl}_{\text {th }}$ and thus prevent corrosion initiation (see Section 3.3).

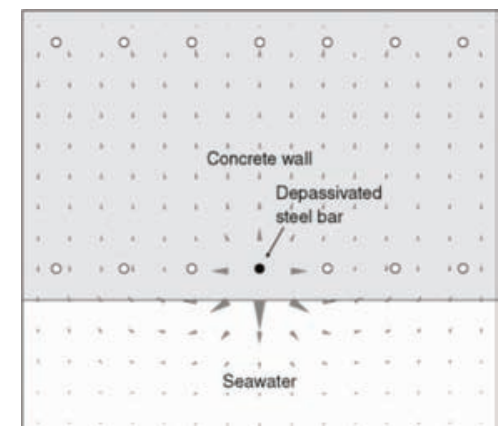

Figure 5. Example of the macrocell current flowing from an active bar in concrete saturated by seawater and surrounding passive bars in a portion of hollow immersed structure; the upper part is exposed to the atmosphere (Della Pergola, Lollini, Redaelli, \& Bertolini, 2013).

\subsubsection{Pitting corrosion propagation}

When pitting corrosion has initiated, a very aggressive environment is produced inside pits, while the protective film is maintained (and even strengthened by alkalinity produced by the cathodic process) on the surrounding passive surface. Corrosion inside pits can reach very high rates of penetration (up to $1 \mathrm{~mm} /$ year in wet and heavily chloride contaminated structures) quickly leading to unacceptable reduction in the crosssection of the reinforcement.

\section{DURABILITY STRATEGIES}

Effects of corrosion of steel bars should be taken into account in the design stage, in order to avoid that any relevant damage will be reached during the design service life. When corrosion of steel is concerned, the service life $t_{1}$ is assumed as the sum of an initiation period and a propagation period: $t_{\mathrm{l}}=t_{\mathrm{i}}+t_{\mathrm{p}}$ (Tuutti, 1982). Initiation of corrosion is usually chosen as limit state for chloride-induced corrosion, due to both safety risks associated with the possible quick reduction in the cross-section of the bars and difficulties in dealing with modelling of corrosion propagation and its structural effects (Fib, 2006). As a consequence, the service life is assumed to be coincident to the initiation time (i.e., $t_{1}=t_{\mathrm{i}}$ ). 
Figure 6 depicts the factors that influence $t_{\text {, }}$, showing that durability targets may be achieved as a combination of measures during design, execution, and management of the structure. The first step is the evaluation of loads applied to the structure, including environmental loads, i.e., physico-chemical actions to which the structure is exposed (e.g., carbonation, chlorides, temperature, humidity, etc.). Then, appropriate specification for the concrete mix composition (e.g., water/cement ratio and type of cement) and properties (e.g., workability, strength, and resistance to cracking), the thickness of the concrete cover, the structural design details, and execution are the main tools available to fulfil the durability target. Furthermore, in aggressive environments and/or when long service life (e.g., $>50$ years) is required, additional protection measures may be adopted, which can be divided into additional preventative protections (e.g., galvanized or stainless steel bars, surface treatment of concrete, use of corrosion inhibitors, cathodic prevention, etc.) and planned controls or maintenance (e.g., regular inspection, monitoring, replacement of non-structural parts, reapplication of a coating, etc.).

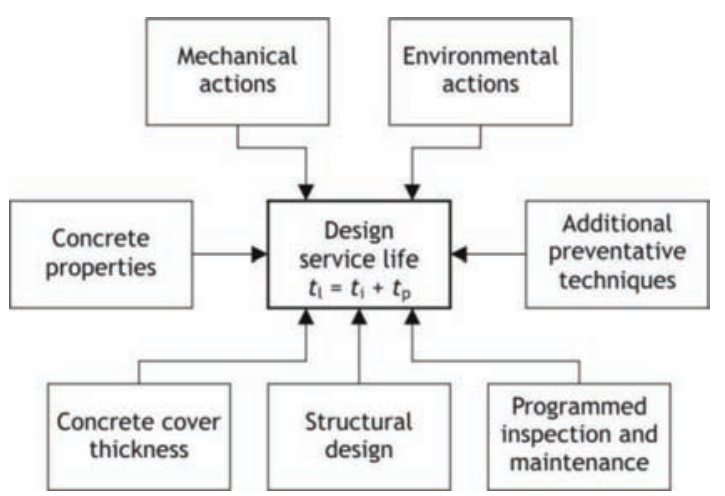

Figure 6. Factors that influence the service life of RC structures in relation to corrosion-induced corrosion (Bertolini, 2008).

\subsection{Prevention provided by the concrete cover}

The definition of an appropriate combination of concrete with sufficiently low permeability to chlorides (and aggressive agents in general) and enough thick cover of the rebar is usually the first step in the design stage. Under moderately aggressive exposure conditions and when a design service life not exceeding 50 years is requested, deemed-to-satisfy rules are often suggested by standards. For instance, in Europe, a standardized method to deal with durability is based on the definition of an exposure class and the subsequent prescriptions regarding the $w / c$ ratio (EN 206, 2013) and the thickness of the concrete cover (EN 1992-1-1, 2004). Of course, this kind of approach may not be exhaustive of all the aspects related to design for durability of reinforced concrete structures.
For structures exposed to aggressive environments, which are mainly related to the presence of chlorides, tailored designs for durability purposes have been proposed. These imply that the designer, on the basis of both the general exposure conditions of the structure and the microclimate, should design every structural element in a way that it can withstand the actual local conditions of exposure during the design service life. To do this, the modelling of degradation mechanisms due to attack by a particular aggressive agent is required, in order to estimate the evolution of deterioration depending on the influencing factors. In the case of chloride-induced corrosion, the "erffunction" approach is generally used, i.e., the initiation time $\left(t_{i}\right)$ is calculated considering the following limit state equation (derived from Fick's second law of diffusion):

$$
C_{s}\left[1-\operatorname{erf}\left(\frac{x}{2 \sqrt{D_{a p p} t_{i}}}\right)\right]-C l_{t h} \leq 0
$$

However, this approach requires a reliable estimation of the apparent diffusion coefficient $\left(D_{\text {app }}\right)$, the surface chloride concentration $\left(C_{s}\right)$, and the chloride threshold value $\left(C l_{\text {th }}\right)$. Design parameters are $x$ (that is the design value of the concrete cover), $D_{\text {app }}$, and $C l_{\text {th }}$, whilst $C_{\mathrm{s}}$ essentially depends on the exposure environment. Very broadly, assuming that $C_{\mathrm{s}}$ and $C l_{\text {th }}$ are known, a combination of $D_{\text {app }}$ and $x$ has to be found that satisfies the above condition. The role of the concrete properties is thus summarized by the apparent diffusion coefficient $D_{\text {app }}$, which actually is related to the concrete composition. Many studies have attempted to measure appropriate values of $D_{\text {app }}$ through short-term tests or analysis of field data (Andrade, Castellote, \& D'Andrea, 2011; Frederiksen, 1996; Mangat \& Molloy, 1994; Thomas \& Bamforth, 1999). These cannot be described in this context, and it suffices here to state that there is no general agreement on the effectiveness of these methods, and there is still discussion about their limits, e.g., their dependence on time of exposure or type of binder.

A wide range of design methods using probabilistic approaches have been proposed. Often the one proposed by the International Federation for structural concrete (Fib, 2006) is considered, which is based on a probabilistic or semi-probabilistic approach similar to that used in the structural design: limit states that indicate the boundary between the desired and the adverse behaviour of the structure are defined. In this model, the concrete resistance to chloride penetration is evaluated by means of an accelerated test, which provides an apparent chloride diffusion coefficient. Usually the rapid chloride migration test proposed by 
Nordtest NT-Build 492 is used to determine the input diffusion coefficient $\left(D_{\mathrm{RCM}}\right)$.

For instance, Figure 7 shows $D_{\mathrm{RCM}}$ values measured on concrete made with ordinary Portland cement and blended cements with various percentages of cement replacement with ground limestone $(L I)$, as a function of water/binder ratio $(w / b)$ and binder content (b). The test results cannot be directly used to predict the chloride penetration in a structure but should be corrected through coefficients that take into account, for instance, the real environmental exposure conditions. Design equations have been set to calculate the failure probability of pre-set performances of the structure as a function of time. The acceptable probability should be selected on the basis of the severity of the adverse event occurring (limit state), although this task is not simple. Design equations, correction parameters, and limitations of the model can be found in the literature (Ferreira, 2012; Fib, 2006; Lollini, Redaelli, \& Bertolini, 2012; Marques, Costa, \& Lanata, 2012; Vorěchovská, Teplý, \& Chromá, 2010).

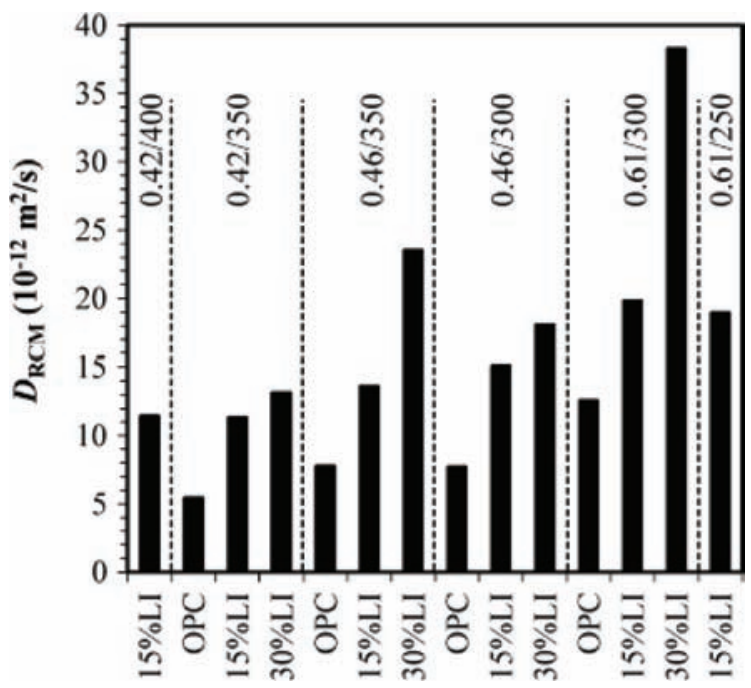

Figure 7. $D_{\mathrm{RCM}}$ coefficients as a function of water/binder ratio, type of binder, and binder dosage measured on concrete cured 28 days (e.g., $0.42 / 400$ means $w / b=0.42$ and $b=400 \mathrm{~kg} / \mathrm{m}^{3}$ ) (Lollini, Redaelli, \& Bertolini, 2014).

To show the possible use of these performance-based model, Figure 8 shows an example of calculation of the probability of failure for the splash zone of a marine structure for which a design service life of 100 years is required. $p_{\mathrm{f}}$, assumed as the probability of initiation of chloride-induced corrosion, is plotted as a function of the average value of concrete cover thickness; the effect of different binders (Portland cement, OPC, and blended cement with $70 \%$ of ground-granulated blast furnace slag, BF) and type of rebars (black steel, galvanized steel, and two types of stainless steels, 1.4307 and 1.4462 according to EN standards) is shown for a water/ binder ratio of 0.45 . From this graph combinations of minimum concrete cover thickness, type of concrete and type of reinforcement which guarantee the service life can be determined, e.g., by considering a target probability, $P_{0}$, of $10 \%$. For instance, for conventional black steel rebars and OPC concrete, it is unfeasible to guarantee the design service life, since a concrete cover even higher than $150 \mathrm{~mm}$ would be required (white circle symbols). Even in concrete made with ground-granulated blast furnace slag cement (BF) and a water/binder ratio of 0.45 , a concrete cover thickness of about $90 \mathrm{~mm}$ would be need (black circle symbols). As it will be discussed in Section 3.2, the use of corrosion resistant rebars (e.g., stainless steel bars) will allow much more reasonable values of concrete cover thickness, even using Portland cement.

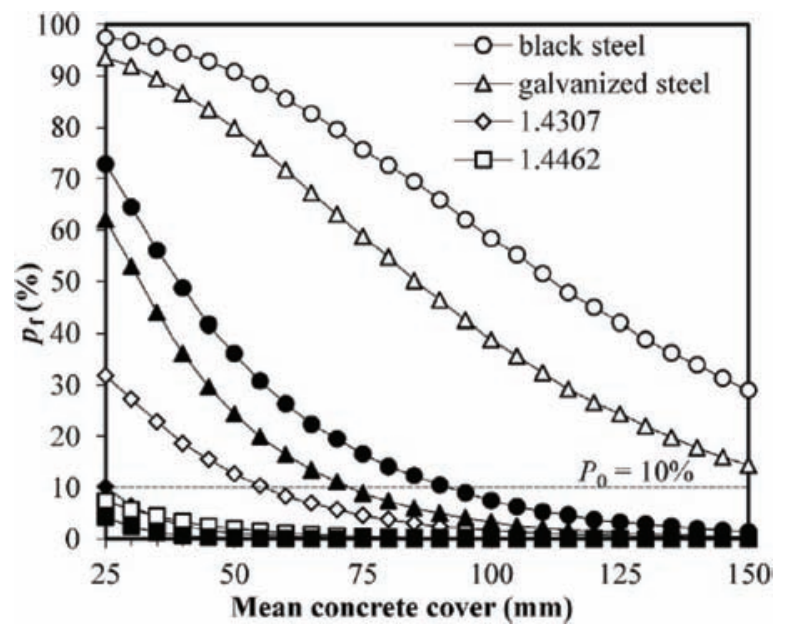

Figure 8. Probability of failure, $p_{f}$, as a function of mean concrete cover thickness, the type of reinforcement, and the type of binder $(\mathrm{OPC}=$ white symbols; $\mathrm{BF}=$ black symbols $)$ calculated for $w / c=0.45$ and a design service life of 100 years of RC element exposed to the splash zone (Lollini, Carsana, Gastaldi, Redaelli, \& Bertolini, 2015).

\subsection{Use of corrosion resistant steel bars: the case of SSR}

Stainless steel rebars (SSR) can be used as a preventative technique for structures exposed to aggressive chloride environments. Specific grades of austenitic and duplex stainless steel are currently used in concrete, as summarized in Table 1.

Traditionally, stainless steel bars are of the austenitic grades $304 \mathrm{~L}$ and $316 \mathrm{~L}$ and duplex 22-05. In recent years, the fluctuations and increase in cost of nickel has led to the proposal of new duplex stainless steels with low nickel and molybdenum contents, especially 23-04 grade. Stainless steel rebars are required to have mechanical properties at least equivalent to those of carbon steel rebars, and weldability is usually guaranteed by controlling the chemical composition, since the corrosion resistance of stainless steels is affected by the presence of a mill scale on their surface. 
Table 1. Approximate chemical composition of some typical grades of stainless steel used for reinforcing bars (Bertolini \& Gastaldi, 2011a).

\begin{tabular}{cccccc}
\hline & & \multicolumn{4}{c}{$\begin{array}{c}\text { Approximate chemical composition } \\
\text { (\% by mass) }\end{array}$} \\
\cline { 3 - 6 } Grade & $\begin{array}{c}\text { Micro- } \\
\text { structure }\end{array}$ & $\mathrm{Cr}$ & $\mathrm{Ni}$ & Mo & $\begin{array}{c}\text { Other } \\
\text { elements }\end{array}$ \\
\hline 304L & Austenitic & $17.5-19.5$ & $8-10$ & - & - \\
316L & Austenitic & $16.5-18.5$ & $10-13$ & $2-2.5$ & - \\
$22-05$ & Duplex & $21-23$ & $4.5-6.5$ & $2.5-3.5$ & $\mathrm{~N}$ \\
$23-04$ & Duplex & $22-24$ & $3.5-5.5$ & $0.1-0.6$ & $\mathrm{~N}$ \\
$21-01$ & Duplex & $21-22$ & $1.4-1.7$ & $0.1-0.8$ & $\mathrm{Mn}, \mathrm{N}$ \\
\hline
\end{tabular}

Although in chloride-contaminated concrete, bars of stainless steel can suffer pitting corrosion such as carbon steel, the different composition of the passive layer produced on the surface of stainless steel allows a remarkable increase in the chloride threshold value. Figure 9, for example, shows the summary of tests carried out on rebars of different grades of stainless steel. It should be considered that, similarly to carbon steel, the evaluation of the chloride threshold is rather difficult, and there are no standardized or generally accepted methods for its evaluation. So results of different authors, who use different techniques are not always comparable (for instance, often tests in solutions are used for a preliminary assessment of the role of the chemical composition or the microstructure of the material, but they do not permit the definition of a chloride threshold level in concrete).

In order to give an indicative picture of the order of magnitude of the chloride content at which traditional stainless steel bars can resist to corrosion initiation, it may be assumed that in non-carbonated concrete, austenitic steel 304L can be safely used in concrete up to $5 \%$ of chloride by mass of cement, and $316 \mathrm{~L}$ and duplex stainless steel even up to or higher than $5 \%$, i.e., for chloride contents that are rarely ever reached in the vicinity of the steel surface. Lower chloride threshold values can be found for recently developed low-nickel stainless steel bars such as 23-04 and especially 21-01 grades (Figure 9). Furthermore, in the presence of a welding scale on the surface of reinforcement, a lower critical chloride content of $3.5 \%$ has to be assumed even for traditional 304L and 316L steels. Even this value will hardly ever be reached in practice. The same reduction takes place if the surface is covered by the black scale formed at high temperature during thermo-mechanical treatments; for this reason, the mill scale is usually removed by the producers by pickling of rebars (sand blasting is less effective as it does not completely free the surface from the oxide scale).
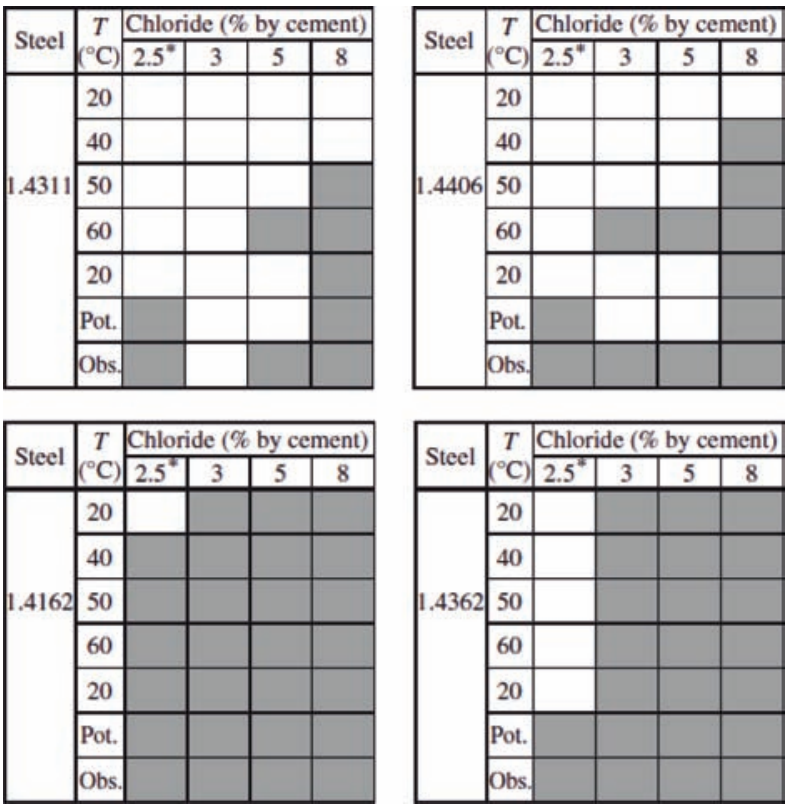

Figure 9. Summary of the results of corrosion tests carried out on bars of stainless steels of grade 304L (1.4311), 306L (1.4406), 2101 (1.4162), and 23-04 (1.4162). Gray cells shows conditions were the stainless steels failed as a function of the chloride content of concrete and temperature (Pot. and Obs. refer to potentiostatic tests at $+200 \mathrm{mV}$ vs. SCE and visual observation carried out at the end of the tests) (Gastaldi \& Bertolini, 2014).

In carbonated concrete, or in the case where the concrete is extensively cracked, the critical chloride contents are remarkably lower. The more highly alloyed stainless steels should be preferred in these more aggressive conditions, e.g., inside road tunnels. It should also be observed that, as shown in Figure 9, the critical chloride content decreases as the temperature increases.

Several grades of stainless steel commercially available offer a wide range of possibilities to designers, in terms of both corrosion resistance and costs. The selection of stainless steel bars should then be made in the framework of a performance-based service life design, where the actual critical chloride threshold should be considered in order to assess the expected service life of the structure. In the example of Figure 8, for instance, it can be observed that even a concrete cover of $25 \mathrm{~mm}$ could fulfil the target probability of failure $P_{0}$ if the high corrosion resistant 22-05 (1.4462) or the less resistant $304 \mathrm{~L}$ (1.4307) is used, in the latter case only in combination with BF cement (black square symbols). These examples are only indicative, since even small variations in the chemical composition, thermo-mechanical treatment or the surface condition may significantly affect the corrosion resistance of stainless steel bars in chloride-bearing concrete. Therefore, the chloride threshold should be measured for any specific type of stainless steel, and its variability should also be evaluated (Lollini, Carsana, Gastaldi, Redaelli, \& Bertolini, 2014a, 2014b). 
In order to optimize the use of stainless steel bars, this could be limited to the most vulnerable parts of a structure, while the combined use of conventional carbon steel bars is possible in those zones where protection provided by the concrete cover is sufficient. It has been clearly shown that when both carbon steel and stainless steel rebars are passive and embedded in aerated concrete, no galvanic effect occurs, since the two types of steel have almost the same free corrosion potential. It was shown that even in the unfortunate case that corrosion would initiate on carbon steel, the macrocell current due to connection with stainless steel is insignificant compared to macrocell that anyway is present between active and passive areas of the carbon steel itself (Bertolini, Gastaldi, Pastore, Pedeferri, \& Pedeferri, 1998).

The additional cost of using stainless steel can thus be drastically reduced by means of a selective use of stainless steel bars, i.e., limited to the most vulnerable parts of the structure. This additional cost must be compared to the cost of repair expected to be saved in the future, multiplied by the probability of its occurrence in the case stainless steels are not used. Several authors have shown that by applying life cycle cost analysis to several types of RC structures exposed to chloride environments, the choice of a suitable type of stainless steel in specific parts of the structure can allow savings on future maintenance expenses that can be much higher than the initial increase in cost.

The improved corrosion resistance of RC structures with SSR bars may also allow to improve the sustainability of concrete constructions. Recently, within the Infravation program (www.infravation. net), a project named SeaCon (http://seacon.umsml.com) has been started with the ambitious aim of demonstrating that it is possible to change the current perspective of limiting the chloride content in concrete and designing durability by preventing chloride penetration. The use of stainless steel bars (or composite FRP bars) may allow to produce concrete with chloride limits much higher than those considered by present standards (or even without limits), so that seawater instead of freshwater for mixing and curing, and chloride-contaminated recycled concrete aggregate (RCA) instead of natural aggregate may be used. If successful, this "greener" concrete would also allow the use of cements without chloride restrictions, thus giving cement manufacturers the opportunity to use solid waste as kiln fuel (co-generation) as well as adding kiln dust (by-product that currently requires disposal) back to the clinker. The study will demonstrate the feasibility of this approach from a technical point of view and evaluate its impact on the sustainability of
$\mathrm{RC}$ structures on the basis of a life cycle analysis and life cycle cost approach.

\subsection{Cathodic prevention}

Since the early 90 s, a special application of cathodic protection of steel in concrete has been developed to prevent corrosion initiation in constructions subjected to chloride penetration. The principles of this technique were formulated by Pedeferri (1995), who named it cathodic prevention in order to distinguish its peculiarities from cathodic protection, applied to control the corrosion rate of corroding steel in chloridecontaminated concrete.

Cathodic prevention consists in the application of a direct current that flows through the concrete from an anode applied on the concrete surface to the reinforcement (cathode). A current density in the range of $1-2 \mathrm{~mA} / \mathrm{m}^{2}$ (of steel surface) is applied to passive reinforcement in new constructions, i.e., before chlorides penetrate the concrete. This technique is aimed at avoiding the initiation of pitting corrosion when subsequent chloride penetration from the environment takes place, by increasing the chloride threshold $\mathrm{Cl}_{\mathrm{th}}$. For any given potential, as the chloride content increases, steel can move from a condition of passivity, where pitting does not initiate, to one of corrosion where pitting initiates and propagates, as shown in Figure 4. There is however an intermediate condition (field $B$ in Figure 4, named "imperfect passivity"), where pitting cannot initiate on passive steel, but may propagate if it has already initiated.

If cathodic prevention is applied to passive steel embedded in concrete exposed to the atmosphere, even a modest lowering of the steel potential can produce a significant increase in the critical chloride content. In fact, the free corrosion potential of steel usually ranges from -200 to $0 \mathrm{mV}$ vs. SCE and pitting corrosion can take place at a chloride content as low as $0.4 \%$ by cement mass. However, a lowering in steel potential of only $100 \mathrm{mV}$ can maintain steel passivity at higher chloride contents. Such polarization leads to conditions of imperfect passivity where pitting corrosion, although it cannot initiate, can propagate. It should therefore be emphasised that cathodic prevention has to be applied before corrosion initiates and must be maintained throughout the entire service life of the structure. If pitting corrosion has initiated, cathodic prevention cannot be applied, since protection of steel (namely, the arrest of ongoing corrosion, which is possible only in field 5 of Figure 4) can be achieved only with a much greater lowering of potential, so that cathodic protection has to be applied instead.

Figure 10 shows the results found with long-term tests aimed at finding an experimental relationship 
between the steel potential under cathodic prevention conditions and the critical chloride content for corrosion initiation. Current densities ranging from 0.4 to $16.8 \mathrm{~mA} / \mathrm{m}^{2}$ were applied to rebars embedded in concrete slabs subjected to ponding with a sodium chloride solution. During 5 years of testing, measurements of steel potential and 4-h decay, i.e., the difference between the potential measured $4 \mathrm{~h}$ after switching off the current and the instantaneous off potential (IR free), were regularly carried out. The application of cathodic current density led to a remarkable polarization of the passive steel. Even a very low current density of $0.4 \mathrm{~mA} / \mathrm{m}^{2}$ was enough to lower the potential by about $150-200 \mathrm{mV}$ and lead to a potential decay higher than $100 \mathrm{mV}$ after $4 \mathrm{~h}$ of depolarization. In time, chloride penetrated the concrete cover, and Figure 11 shows the chloride content measured on the steel surface at the time when corrosion initiation was detected (i.e., $\mathrm{Cl}_{\mathrm{th}}$ ). These results confirmed that cathodic prevention in aggressive environments may be achieved with current densities in the range of $1.5-2 \mathrm{~mA} / \mathrm{m}^{2}$. In fact, full prevention of corrosion on steel in contact with concrete with $3 \%$ of chloride by mass of cement was guaranteed by a current density of $1.7 \mathrm{~mA} / \mathrm{m}^{2}$. Current densities of 0.8 and $0.4 \mathrm{~mA} / \mathrm{m}^{2}$ could not prevent corrosion initiation; however, they led to an attack less severe than in steel with no cathodic current applied.

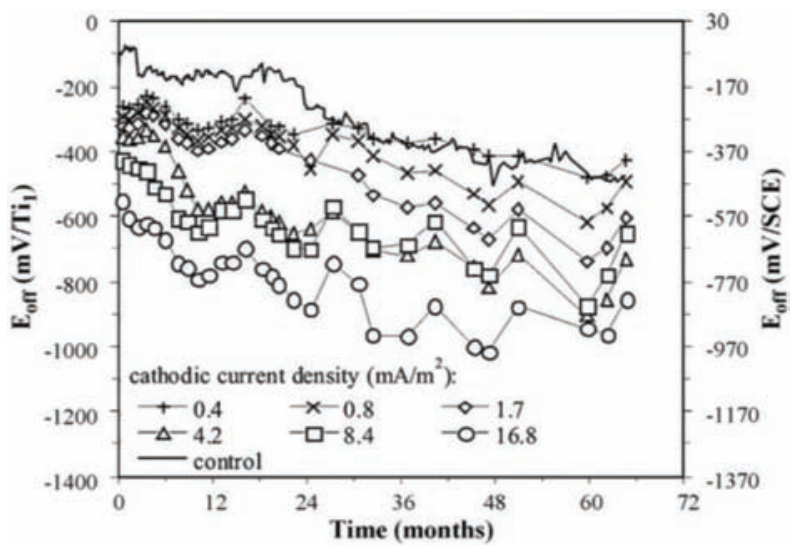

Figure 10. Instant-off values of steel potential measured vs. activated titanium electrodes on steel slabs with different cathodic applied current densities and free corrosion values of steel potential in the (un-polarized) control slab, as a function of time (Bertolini et al., 2009).

The potential decay measured during 4-h depolarization tests proved to be a reliable method for monitoring cathodic prevention. Since decay values always higher than $100 \mathrm{mV}$ were measured on passive steel, the $100-\mathrm{mV}$ decay criteria commonly used for monitoring cathodic protection can also be applied to cathodic prevention.

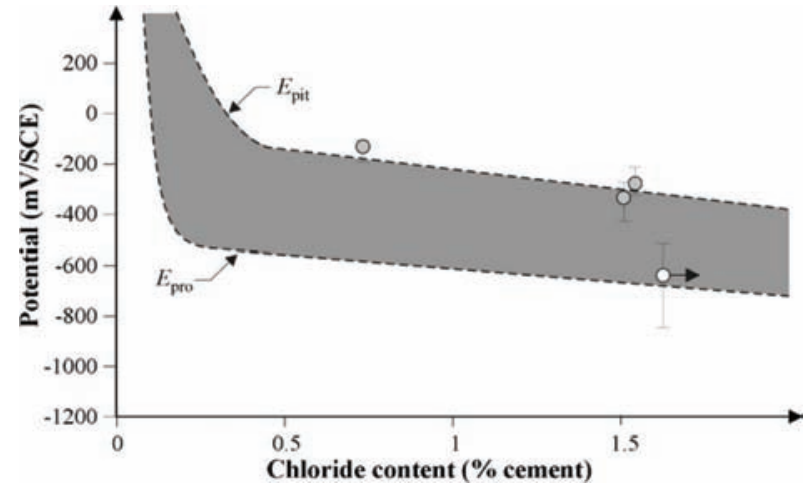

Figure 11. Correlation between potential of passive steel and chloride content at steel depth when corrosion initiated (white symbol with arrow refers to a slab where corrosion did not initiate), compared to Pedeferri's diagram of Figure 4 (Bertolini et al., 2009).

It should be observed that the values of current density of $1.5-2 \mathrm{~mA} / \mathrm{m}^{2}$ required for cathodic prevention are about one order of magnitude lower than current densities required for cathodic protection (applied to structures where corrosion has already initiated). This has an important practical consequence on the protection of structures with several layers of reinforcement. In fact, in reinforced concrete structures, depending on the conditions of humidity and the concrete composition, 70-90\% of the current fed by the anode is absorbed by the nearest layer of reinforcement; only a small fraction of the current reaches the deeper mats of rebars (Bertolini, Bolzoni, Cigada, Pastore, \& Pedeferri, 1993). In order to polarize the deeper mats as well, it is necessary to increase the current density applied to the first mat. However, the polarization induced on the first mat cannot be excessive; in pre-stressed structures, in order to avoid hydrogen embrittlement of high strength strands, steel potential should not reach values lower than $-900 \mathrm{mV}$ vs. SCE. Experimental testing and computer modelling showed that cathodic prevention has a higher "throwing power" than cathodic protection. Because of the low polarization required, and thus of the low risk of reaching potential values lower than $-900 \mathrm{mV}$ vs. SCE, cathodic prevention can also be safely applied to pre-stressed concrete without inducing hydrogen embrittlement on the high strength steel.

Cathodic prevention was first applied in the early 90 s in Italy to new viaducts subjected to the action of de-icing salts, even in the presence of high strength steel of pre-stressing strands (Bazzoni, Bazzoni, Lazzari, Bertolini, \& Pedeferri, 1996). After cathodic prevention was applied to reinforced and prestressed viaducts in Italy, it was applied worldwide to many other structures subjected to chloride penetration. 
The above-mentioned applications of cathodic prevention are based on the use of extended anodes on the surface of concrete (e.g., activated titanium mesh) and a current feeder, as in the application of cathodic protection to corroding steel in concrete exposed to the atmosphere. Because of the high throwing power of cathodic prevention, however, the use of local sacrificial anodes has also been proposed for special purposes.

The use of embedded sacrificial zinc anodes in combination with patch repair in chloridecontaminated concrete has been proposed as a means of preventing corrosion of the reinforcing bars surrounding the repair due to macrocell effects. In order to overcome the initiation of corrosion at incipient pits (surrounding the repaired area) and provide cathodic prevention to the steel adjacent to the repair, the use of sacrificial anodes embedded near the periphery of the repair patches was proposed by Sergi and Page (1999). A special anode consisting of zinc encased in a high alkalinity mortar saturated with lithium oxide was used, which proved to provide continue protection (namely, cathodic prevention) to the surrounding bars even when a chloride content of $0.8 \%$ by cement weight was left in the original concrete. Results of inspection 10 years after installation on a real structure confirmed the effectiveness of this preventative technique (Sergi, 2011).

Laboratory tests showed that cathodic prevention, thanks to its high throwing power, can be applied to columns of marine structures by means of submerged sacrificial anodes. Experimental tests carried out on reinforced concrete columns with steel embedded both in chloride-free concrete and chloride-contaminated concrete showed that sacrificial anodes may be more effective in preventing corrosion initiation (i.e., in providing cathodic prevention) than in controlling ongoing pitting corrosion (i.e., in guaranteeing cathodic protection). For instance, Figure 12 shows that passive bars in chloride-free concrete could be polarized more than $100 \mathrm{mV}$ even at heights above $1 \mathrm{~m}$. FEM models allowed to see that although current and potential distributions are influenced by the geometry of the column and of sacrificial anodes as well as concrete resistivity, the height of steel protection above the sea level is always much higher in the case of cathodic prevention than in the case of cathodic protection (Figure 13).

These results clearly show that sacrificial anodes can prevent corrosion in the part of pillars in marine structures which is often most critical, i.e., a few metres above sea level, while they are not effective in protecting corroding steel.

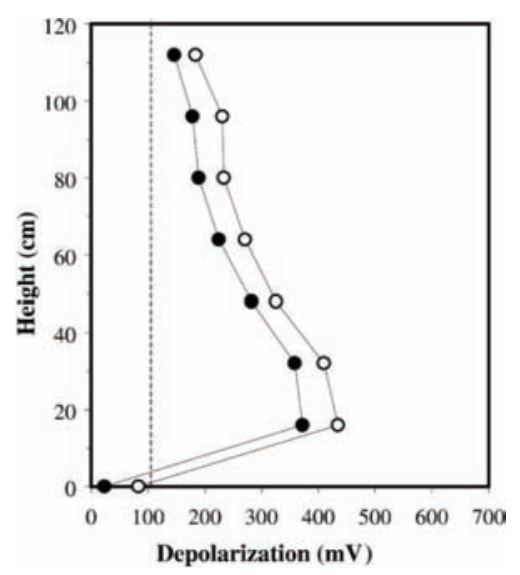

Figure 12. Four-hour depolarization of bars in a pile protected with a zinc sacrificial anode in the seawater, as a function of the height above the water level (Bertolini, Gastaldi, Pedeferri, \& Redaelli, 2002).

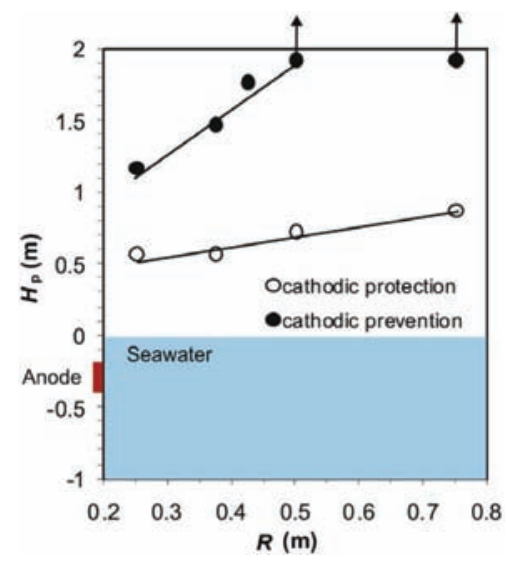

Figure 13. Height of protection evaluated from FEM models for a pile in the splash zone, as a function of the pile radius $(R)$, in the case of cathodic protection and cathodic prevention (Bertolini \& Redaelli, 2009b).

\section{CONCLUDING REMARKS}

The paper has introduced some of the key aspects of chloride-induced corrosion of steel embedded in concrete and their influence on the service life of reinforced concrete structures. Several approaches for the long-term prevention of corrosion have been mentioned, showing the tools available to the designers of structures exposed to aggressive environments. A summary of the studies recently carried out in the research group of the authors, in agreement with results of many other researchers, has shown that the protection provided by the concrete cover to conventional carbon steel bars may be improved by reducing the chloride permeability of concrete through the use of different types of pozzolanic additions, which may decrease the apparent diffusion coefficient of concrete. Nevertheless, performance-based models suggest that in aggressive conditions of alternate wet and dry cycles with chlorides solution (such as in the 
splash zone of marine structures), even in the case of impervious concrete, extremely high (and in practical unfeasible) thickness of concrete cover would be required to guarantee a design service life above 50 years.

In this case, the use of additional preventative measures is necessary. Stainless steel rebars may supply a reliable and maintenance-free solution, provided that an appropriate grade of stainless steel is selected, among those nowadays available on the market. Alternatively, service life of structures with conventional carbon steel rebars may be prolonged by the application of a tailored cathodic prevention system, which should be applied from the construction phase (or, in any case, before corrosion initiates on the bars) and should be managed throughout the service life of the structure with appropriate monitoring and maintenance of the anodic system.

\section{REFERENCES}

Alonso, C., Andrade, A., \& Gonzales, J. A. (1988). Relation between resistivity and corrosion rate of reinforcements in carbonated mortar made with several cement types. Cement and Concrete Research, 8, 687.

Alonso, M. C., \& Sanchez, M. (2009). Analysis of the variability of chloride threshold values in the literature. Materials and Corrosion, 60(8), 631-637.

Andrade, C., Castellote, M., \& D'Andrea, R. (2011). Measurement of ageing effect on the chloride diffusion coefficients in cementitious matrices. Journal of Nuclear Materials, 412, 209-216.

Andrade, C., Maribona, I. R., Feliu, S., Gonzalez, J. A., \& Feliu, S., Jr. (1992). The effect of macrocells between active and passive areas of steel reinforcements. Corrosion Science, 33, 237-249.

Angst, U., Elsener, B., Larsen, C. K., \& Vennesland, Ø (2009). Critical chloride content in reinforced concrete $-\mathrm{A}$ review. Cement and Concrete Research, 39, 1122-1138.

Arup, $H$. (1983). The mechanisms of the protection of steel by concrete. In A. P. Crane (Ed.), Corrosion of reinforcement in concrete construction (pp. 151-157). Chichester, England: Hellis Horwood.

Bazzoni, A., Bazzoni, B., Lazzari, L., Bertolini, L., \& Pedeferri, P. (1996). Field application of cathodic prevention on reinforced concrete structures. NACE International Corrosion/96 Conference, Paper 96312.

Bertolini, L. (2008). Steel corrosion and service life of reinforced concrete structures. Structure and Infrastructure Engineering, 4(2), 123-137.
Bertolini, L. (2011). A tribute to Pietro Pedeferri's contribution to the knowledge on corrosion of steel in concrete and its prevention. Materials and Corrosion, 62(2), 96-97.

Bertolini, L., Bolzoni, F., Cigada, A., Pastore, T., \& Pedeferri, P. (1993). Cathodic protection of new and old reinforced concrete structures. Corrosion Science, 35(5-8), 1633-1639.

Bertolini, L., Bolzoni, F., Gastaldi, M., Pastore, T., Pedeferri, P., \& Redaelli, E. (2009). Effects of cathodic prevention on the chloride threshold for steel corrosion in concrete. Electrochimica Acta, 54(5), 1452-1463.

Bertolini, L., Carsana, M., Gastaldi, M., Lollini, F., \& Redaelli, E. (2011a). Corrosion assessment and restoration strategies of reinforced concrete buildings of the cultural heritage. Materials and Corrosion, 62(2), 146-154.

Bertolini, L., Carsana, M., Frassoni, M., \& Gelli, M. (2011b). Pozzolanic additions for durability of concrete structures. Proceedings of Institution of Civil Engineers: Construction Materials, 164(6), 283-291.

Bertolini, L., Carsana, M., Gastaldi, M., Lollini, F., \& Redaelli, E. (2011b). Corrosion assessment and restoration strategies of reinforced concrete buildings of the cultural heritage. Materials and Corrosion, 62(2), 146-154.

Bertolini, L., Carsana, M., \& Pedeferri, P. (2007). Corrosion behaviour of steel in concrete in the presence of stray current. Corrosion Science, 49, 1056-1068.

Bertolini, L., Elsener, B., Pedeferri, P., Redaelli, E., \& Polder, R. (2013). Corrosion of steel in concrete: Prevention, diagnosis, repair (2nd ed.). Weinheim, Germany: Wiley VCH.

Bertolini, L., \& Gastaldi, M. (2011a). Corrosion resistance of low-nickel duplex stainless steel rebars. Materials and Corrosion, 62(2), 120-129.

Bertolini, L., Gastaldi, M., Pastore, T., Pedeferri, M. P., \& Pedeferri, P. (1998, December 7-11). Effects of galvanic coupling between carbon steel and stainless steel reinforcement in concrete. International Conference on "Corrosion and Rehabilitation of Reinforced Concrete Structures", Federal Highway Administration, Orlando.

Bertolini, L., Gastaldi, M., Pedeferri, M. P., \& Redaelli, E. (2002). Prevention of steel corrosion in concrete exposed to seawater with submerged sacrificial anodes. Corrosion Science, 44(7), 1497-1513.

Bertolini, L., \& Redaelli, E. (2009a). Depassivation of steel reinforcement in case of pitting corrosion: Detection techniques for laboratory studies. Materials and Corrosion, 60(8), 608-616.

Bertolini, L., \& Redaelli, E. (2009b). Throwing power of cathodic prevention applied by means of 
sacrificial anodes to partially submerged marine reinforced concrete piles: Results of numerical simulations. Corrosion Science, 51(9), 2218-2230.

Carsana, M., \& Bertolini, L. (2015). Corrosion failure of post-tensioning tendons in alkaline and chloridefree segregated grout: A case study. Structure and Infrastructure Engineering: Maintenance, Management, Life-Cycle, 11(3), 402-411.

Carsana, M., \& Bertolini, L. (2016). Characterization of segregated grout promoting corrosion of posttensioning tendons. ASCE's Journal of Materials in Civil Engineering, doi:10.1061/(ASCE)MT.19435533.0001451

Carsana, M., Frassoni, M., \& Bertolini, L. (2014). Comparison of ground-waste-glass with other supplementary cementitious materials. Cement and Concrete Composites, 45, 39-45.

CEB. (1992). Durable concrete structures. Committee Eurointernational du Beton. Bulletin d'information No. 183.

Collepardi, M., Marcialis, A., \& Turriziani, R. (1972). Penetration of chloride ions into cement pastes and concretes. Journal of American Ceramic Society, 55, 534.

Della Pergola, A., Lollini, F., Redaelli, E., \& Bertolini, L. (2013). Numerical modeling of initiation and propagation of corrosion in hollow submerged marine concrete structures. Corrosion, 69(12), 1158-1170.

EN 1992-1-1. (2004). Eurocode 2: Design of concrete structures - Part 1-1: General rules and rules for buildings. European Committee for Standardization.

EN 206. (2013). Concrete - Specification, performance, production and conformity. European Committee for Standardization.

Ferreira, R. M. (2012). Implication on RC structure performance of model parameter sensitivity: Effect of chloride. Journal of Civil Engineering Management, 16(4), 561-566.

Fib. (2006). Model code for service life design. Lausanne, Switzerland: International Federation for Structural Concrete. Bulletin No. 34.

Frederiksen, J. M. (Ed.). (1996). HETEK, chloride penetration into concrete, State of the art. Transport processes, corrosion initiation, tests methods and prediction models (Report No. 53). The Road Directorate, Copenhagen.

Gastaldi, M., \& Bertolini, L. (2014). Effect of temperature on the corrosion behaviour of lownickel duplex stainless steel bars in concrete. Cement and Concrete Research, 56, 52-60.

Glass, G. K., \& Buenfeld, N. R. (1997). Chloride threshold level for corrosion of steel in concrete. Corrosion Science, 39, 1001-1013.

Lollini, F., Carsana, M., Gastaldi, M., Redaelli, E., \& Bertolini, L. (2014a). Durability design of concrete structures with corrosion resistant reinforcement. Bjegović, D., Beushausen, H., Serdar, M (Eds.), RILEM Proceedings of the International Workshop on Performance-Based Specification and Control of Concrete Durability (pp. 241-248), Zagreb, Croatia: RILEM Publications s.a.r.I.

Lollini, F., Carsana, M., Gastaldi, M., Redaelli, E., \& Bertolini, L. (2014b). Performance-based durability design of reinforced concrete structures with stainless steel bars. Metallurgia Italiana, 106(7/8), 17-21.

Lollini, F., Carsana, M., Gastaldi, M., Redaelli, E., \& Bertolini, L. (2015). The challenge of the performance-based approach for the design of reinforced concrete structures in chloride bearing environment. Construction and Building Materials, 79, 245-254.

Lollini, F., Redaelli, E., \& Bertolini, L. (2012). Analysis of the parameters affecting probabilistic predictions of initiation time for carbonation-induced corrosion of reinforced concrete structures. Materials and Corrosion, 63(12), 1059-1068.

Lollini, F., Redaelli, E., \& Bertolini, L. (2014). Effects of Portland cement replacement with limestone on the properties of hardened concrete. Cement and Concrete Composites, 46, 32-40.

Lollini, F., Redaelli, E., \& Bertolini, L. (in press). Investigation on the effect of supplementary cementitious materials on the critical chloride threshold of steel in concrete. Materials and Structures, doi:10.1617/s11527-0150778-0

Manera, M., Vennesland, $\varnothing$, \& Bertolini, L. (2008). Chloride threshold for rebar corrosion in concrete with addition of silica fume. Corrosion Science, 50(2), 554-560.

Mangat, P. S., \& Molloy, B. T. (1994). Prediction of long term chloride concentration in concrete. Materials and Structures, 27, 338-346.

Marques, P. F., Costa, A., \& Lanata, F. (2012). Service life of RC structures: Chloride induced corrosion: Prescriptive versus performancesbased methodologies. Materials and Structures, 45, 277-296.

Page, C. L. (2002, September 22-27). Advances in understanding and techniques for controlling reinforcement corrosion. 15th International Corrosion Congress, Granada.

Page, C. L., \& Page, M. M. (Eds.). (2007). Durability of concrete and cement composites. Woodhead.

Page, C. L., \& Treadaway, K. W. J. (1982). Aspects of the electrochemistry of steel in concrete. Nature, 297, 109-116.

Pedeferri, P. (1995). Cathodic protection and cathodic prevention. Construction and Building Materials, 10, 391-402. 
Redaelli, E., Bertolini, L., Peelen, W., \& Polder, R. (2006). FEM-models for the propagation period of chloride induced reinforcement corrosion. Materials and Corrosion, 57(8), 628-635.

Schiegg, Y., Audergon, L., Elsener, B., \& Böhni, H. (2001, September 30-October 4). Online monitoring of the corrosion in reinforced concrete structures. International Conference on Eurocorr/01, European Federation of Corrosion, Riva del Garda.

Sergi, G. (2011). Ten-year results of galvanic sacrificial anodes in steel reinforced concrete. Materials and Corrosion, 62(2), 98-104.

Sergi, G., \& Page, C. L. (1999, August 30September 2). Sacrificial anodes for cathodic prevention of reinforcing steel around patch repairs applied to chloride-contaminated concrete. International Conference on Eurocorr/99,
European Federation of Corrosion, Aachen, p. 248.

Thomas, M. D. A., \& Bamforth, P. B. (1999). Modelling chloride diffusion in concrete. Effect of fly ash and slag. Cement and Concrete Research, 29, 487-495.

Tuutti, K. (1982). Corrosion of steel in concrete. Stockholm, Sweden: Swedish Foundation for Concrete Research.

Vassie, P. R. (1984). Reinforcement corrosion and the durability of concrete bridges. Proceedings of the Institution of Civil Engineers, Part 1, 76, 713. Paper 8798.

Vorěchovská, D., Teplý, B., \& Chromá, M. (2010). Probabilistic assessment of concrete structure durability under reinforcement corrosion attack. Journal of Performance of Construction Facilities, 24(6), 571-579. 